\title{
Carving a Niche within the Regional Contemporary Society as One Southeast Asia through Drama
}

\author{
William J. Cabasaan Jr
}

\begin{abstract}
Drama mirrors life. Therefore, drama becomes not only an interesting topic to dwell on but more academic and scholarly. This paper looks into drama as it carves a niche within the regional contemporary society to effect one Southeast Asia. This study attempts to identify the selected dramas which express the identity of the contemporary society of Southeast Asia. Also, it determines the commonalities and differences of these dramas in the contexts of its themes, conflict, types, characters, language, and setting. Furthermore, it finds answer to how these dramas carve its niche in the contemporary society to overcome barriers between and among people of Southeast Asia and more importantly how these dramas demonstrate the potential to represent Southeast Asia of its place in the world emphasizing the historical, cultural, social, educational, religious, political, and economic environs.

In the analysis of the paper, it was found that dramas selected expressed the identity of the contemporary Southeast Asia, there are shared commonalities and differences among the selected dramas of Southeast Asia. Thus, a move for one Southeast Asia can be deemed possible. Problems, issues, and perspectives presented in the Southeast Asian dramas help overcome barriers between and among its people. Therefore, a niche can be carved for Southeast Asian dramas distinctly its own; and the potential to represent Southeast Asia through its dramas is great as demonstrated by the influence of the Asian drama, religious and culture beliefs as well as other varied influences.
\end{abstract}

Index Terms - Drama, southeast Asia, theater, art.

\section{INTRODUCTION}

Drama is a unique testament of written cultures. And because of the presence of such documentations, drama becomes not only an interesting topic to dwell on but more academic and scholarly. This research looks into drama as it carves a niche within the regional contemporary society to effect one Southeast Asia. This study attempts to identify the selected dramas which express the identity of the contemporary society of Southeast Asia. Also, it determines the commonalities and differences of these dramas in the contexts of its themes, conflict, types, characters, language, and setting. Likewise, it finds answer to how these dramas carve its niche in the contemporary society to overcome barriers between and among people of Southeast Asia and more importantly how these dramas demonstrate the potential to represent Southeast Asia of its place in the world emphasizing the historical, cultural, social, educational, religious, political, and economic environs.

Drama can be studied in the classroom in terms of imagery,

Manuscript received September 28, 2015; revised December 20, 2015.

W. J. Cabasaan Jr is with the Graduate School, Centro Escolar University, Philippines (e-mail: chunch20@yahoo.com). character, and theme; but, study of this sort takes place before and after the event. It is a form of preparation for or follow-up to the experience; the experience is the performance itself [1]. Cheever (2015) stated that the historical backdrop of drama extends over to some of humankind's soonest civilizations and what could be seen now are something that individuals have appreciated for hundreds of years. He said that dramatization began back in old Greece. A large number of the plays composed amid the Classical period, from $525 \mathrm{BC}$ to $385 \mathrm{BC}$, are still performed today. Antigone, Oedipus Rex and Medea are among the plays composed amid this time. Not just are these plays still prominent as showy creations, they additionally extraordinarily impacted writers all through history.

Diamonds (2012) narrated that Southeast Asian drama has been customary considered from the point of view of the significant customs of China, Japan, India and Indonesia [2]. This research will show that drama as a literary form of selected Southeast Asian countries cater to a distinctive and captivating picture of the quickly changing social orders in the area. Carving a niche doesn't only analyze the recorded and social settings additionally associate show to the social, political, semantic and religious arousing in the contemporary times.

A drama may be called truly Southeast Asian, not only if it reflects Asian culture, not only if it answers the needs of entertainment, exposure and exhortation, but most especially, if what it exhorts to is the final liberation of the masses [3]. Writing drama during the contemporary period, was a time when the Southeast Asian countries were struggling to come out of the devastation of World War II and sustain their economic stability despite the Asian financial crisis.

The study intends to highlight drama in carving a niche within the regional contemporary society as one Southeast Asia. Specifically, the researcher sought answers to the following questions in order to do this, the following problems are hereby enumerated:

1) What are the selected dramas which express the identity of the contemporary society of Southeast Asia?

2) What are the commonalities and differences of these dramas in the following contexts: Themes, Conflict, Types, Characters, Language, and Setting?

3) How can these dramas carve its niche in the contemporary society to overcome barriers between and among people of Southeast Asia?

4) How do these dramas demonstrate the potential to represent Southeast Asia in the world?

The study is anchored on the assumptions that drama as a literary art form is not only an entertainment medium but also a powerful tool to unite people. Dramas which will be selected best represent the identity of the nation where it 
belongs; and the similarities and identified differences in the selected dramas carved a niche in each of the countries in Southeast Asia within the regional contemporary society.

\section{PRELIMINARY}

This research takes a fresh look on drama as an art form to bring its beautiful message that drama influence survives, far and wide. It is against the background of this milieu that people now ask themselves, that they now question, the relevance of art for their lives. Has art indeed become irrelevant in people's lives? And then, as artists, as a people for whom art is ever present if rarely acknowledged, man answers resoundingly, "Art will never become irrelevant... but..." But, perhaps people must once again, through their works, search for how art can uplift spirits, sagging in the depression of man's political sorrows. And through their productions, point towards some sort of solution to unsolvable problems [4]. The greatest philosopher has once said " Tell me and I forget, Teach me and I may remember, involve me and I will learn" this connection has something to do between doing and learning. Drama is an artistic representation of life and conveys playwright's vision in creating a picture of man's native characteristics against the backdrop of a complex society. Though drama is marginalized by the popular media like television, film and internet, it still creates an identity by attracting theater goers and reflects the ambitions and concern in instant and edgy ways because drama sharpens people's consciousness of national tradition and culture.

This research is anchored on the ideas of "Unity in Diversity" and "United in Diversity", which are both significant to ASEAN integration as the motto of ASEAN 2015 convention.

An epigraph written for a book by Novak (1983) reads as follows:

Unity in diversity is on the top of the possible fulfillment of a civilization, an evidence to the better gentle possibilities of the man's existence [5]. This fulfillment can come into reality through wistful concern for choice, in an realm of societies trust (Novak, 1983 as cited in Birch, 1983)

Drama theory in Moral Criticism and Dramatic Construction discusses Aristotle's view on drama as "an imitation of an action that is serious, complete and of certain magnitude; in language embellished with artistic ornaments with incident arousing pity and fear to purgation of catharsis." Since Aristotle saw dramatic art as a medium he proposed organize ideas that drama as an art form encompasses a broad range of human activity [6].

The researcher have also used Formalism Theory in which Formalism asserts that a literary masterpiece has specific integral peculiarities, which connects formalism to literary criticism and deconstruction, creating a more significant meaning on any cultural aspect such as the language, identity, behaviour and one's existence [7]. Another fundamental stage of appreciating and understanding drama is through reader response criticism view, in which readers' take to dramatic literatures as dynamic to explain the denotation of the text, although, reader-response criticism can hold a lot of distinctive technique. There is a big role of the reader in analysing and appreciating the context of a written work. The reader provides their own meaning on symbols which are used in an available literature. All ideas carry the message of being together that is similar to what the researcher thinks in order to become one region or one Southeast Asia using drama as its bridge.

\section{DiscUSSION AND ANALYSIS OF DATA}

The study is a qualitative research which attempts to describe how the contemporary society of the Southeast Asian region carves its niche through drama. To be more specific, this paper employs content analysis. The dramas from Malaysia, Philippines, Singapore and Thailand were content analyzed so as to find out the differences and most importantly the similarities of the selected Southeast Asian countries in their efforts to form a regional contemporary society though drama. Through this, common themes were identified, patterns or structures can be explained and situations in the region can be described.

A criteria for the selection of the selected dramas has been conceptualized. The dramas to be selected are all one-act plays which have been staged and exhibited either in the home country or elsewhere. The selected dramas have been staged and exhibited during the contemporary period; and these dramas are literary winners of their respective countries. Copies of the scripts of these dramas will then be obtained for content analysis. After which, comparisons as to the similarities and differences of these dramas will then be identified and described in order to cull out common themes, patterns and situations.

The essence of drama is contained in the basic idea of the "imitation of movement of the world" or as Aristotle stated in his famous definition of tragedy as the imitation of the action [8]. A freer interpretation would mean the representation or impersonation of an event, real or imagined.

Romano, Papa \& Saulle (2015) emphasized that the function of drama has been accustomed within the timeline of history from Aristotle, who noted that theater had been a medium for men to discharge emotions, from the start of the refined shifting in education, where highlight was put into "doing" than memorizing. In this quintessential resource: 'The Arts as Meaning Makers', written by Claudia E. Cornett and Katharine L. Smithrim, there are 12 all-important keys that the authors strongly agree to be essential to consider.

There is no doubt that drama has risen as one of the most popular means of mass communication in contemporary Southeast Asia. Theater venues have become as important to Asians today as temple and churches were in last century [9]. Because dramas have become one of the most important means of communication, it is high time that Asians examined the values encountered in and propagated by, the dramatic literatures.

Majority of ASEAN dramas, have touched the theme on Perseverance and Self-esteem which is obvious in the play entitled Inside Outside Door which believes in "acceptance starts with you" if man himself cannot see his worth, then don't expect somebody there will see it. No one knows who he really is except him. It is a story of an authoritarian 
between the father and his daughter. Xiao Fang decides to introduce her boyfriend to her father, though the father is very strict and full of ideologies on family reputation he still tried to win the heart of her daughter by accepting latters soon to be husband.

Another drama entitled After Us, determines the perseverance of the family as it helps the community during the reconstruction period. Muthiah, a Malaysian father, was able to discern the importance of nationalism and patriotism through the help of his children. Though naturally practical, he and his wife Santha have had three children who were blessings in the society; Sankar, who is into Community Centre Cultural Group, Leela, who is into People's Association and Kumar, who is into Army. After all the contemplations, circumstances and exploits, Muthiah finally found himself on his role in the society.

Ondoy from the Philippines, comically enlightens the self-esteem and perseverance of the couple being stranded for so many hours at the middle of a catastrophe The drama was situated in a roof at the height of a severe storm and massive flooding. Given the layers of problems such as sins, mistakes and shortcomings, the roof served as the last safest place for the couple Mercy and Obet, who are trying to survive the dilemma brought also by an overflowing flood. The scenario silently reveals the order not to be read or so, not to forget or try to forget, but to learn to forgive and indulge oneself to fully accept one another.

Gagamutin ang Bayan, also from the Philippines, employs the perseverance of the nuisance candidate and how they can be win in an election. The one-act play is a story of a respected young doctor, Jess Resureccion who runs for mayor aiming to introduce positive changes in the community. Doc Resureccion visited Boy Pogi's home in a poor fishing village and tried to convince Boy to withdraw his candidacy in exchange of money and promising him of a better future. Until the play, with its increasingly savage dialogue, took a shocking turn near the end.

The most treasured possession of the Asians could be their Family [10]. This is a classic example in most dramas of Southeast Asia. The drama Singapore Bride Groom was efficient enough in making the family as a treasure that everyone can possess. The play tackles the marriage proposal of the two families. These two families have a different religion and different class of living. It was in the line when Gopalsamy said "By God's grace she has been saved. There, they are all coming. Let us look in the wedding

arrangement first. "'[11]

Gopalsamy knew the truth about his son-in-law not studying in the university, he is a father of a child already and splurging thousands of dollars in film production. That is the reason why Gopalsamy, the heroine's father, after all the doubts still agreed that Sundaralingan(hero) and Selvi(heroine) can get married. It was in the scene also when Gopalsamy said

“That's right! But everyone should know what I intend to give my son-in-law... (He takes out the notebook and starts writing)."

Gopalsamy, despite of all costly dowries being asked from him would still give what he has, just to continue the marriage for his daughter. He is a kind of father that will do anything for his daughter's sake, but then, since Gopalsamy already knew the truth about his son-in-law to be, he did not hesitate to go back to Singapore to feel sorry to Sundaralingan. They finally continued the arranged marriage of Sundaralingan and Selvi. Gopalsamy saved his daughter's hand from the wrong person

\section{A. Environmental Protection and Sustainable Development}

Singapore's The Silly Little Girl, provided an awareness on the importance of protecting the planet earth. The tale is a conversation between an old tree that had leaves at the bottom instead on the top, and a little girl who used to talk to it everyday. While the girl was humming she noticed the old tree was swaying, so she realized if it can hear then it can understand as well as it may talk.

"I have always believed that a blighted urban landscape, a concrete jungle destroys the human spirit. We need the greenery of nature to lift our spirits."

- Mr Lee Kuan Yew, 1995

From Garden City to City in a Garden, Singapore has been utterly transformed by the work of Singapore's late founding father, Mr Lee Kuan Yew, whom they dub affectionately as the country's Chief Gardener.

P'ra Ruang from Thailand has also the same theme when it comes to environmental awareness and protection. The play, P'ra Ruang, is about the City father of Lavo who was loved by his people because of being brilliant, kind and good-hearted leader. Lavo City experienced drought and they still have to give water-tribute to Khom, so P'ra Ruang came up with the idea of creating baskets that will carry the required volume of water. Everyone was amazed with P'ra Ruang so he was offered to be the King of Sukhotai and he accepted it.

\section{B. Unconditional Love}

Thailand's Dear Moon emphasized on the theme: "Love can overcome all boundaries". This is supported by the end scene of the play in which Chitr and Chiam are reunited in spite of all the hardships they have gone through (which were all idiotically created by themselves). Dear Moon is about two people who are passionately in love with each other. But, they have to face hurdles to prove their love and sincerity with one another. They faced a long-distanced relationship with no assurance. There is also a meddling of other lovers into the play.

They said that love is the universal language, and it also embraced the dramas entitled: Inside Outside Door, discusses that love has no boundaries; and Singapore Bridegroom which considers religion and other culture as secondary requirements to make the relationship strong and last forever. Another play entitled Luad Suphan tells that to love needs a big sacrifice. This drama is centered to Duangchan, a beautiful young woman together with her relatives in Suphan, were oppressed by the Burmese. Her pleads were not answered, and when she returns to the forest she discovers her parents death, prompting her to fight against the oppression. As they reach the king face-to-face, all of the 
community that was left, were all killed. No one was left from their community, and the oppression continues in Siam.

\section{Humanity In Spite of Diversity}

Pra Ruang of Thailand kept the idea that "The most powerful force ever known in the planet is human cooperation - a force for construction and destruction."

In the play, people of Lavo was able to give the water-tribute, aside from the brilliance of P'ra Ruang , because of their cooperation. On the first act, P'ra Ruang ordered his fellow and said,

\section{"All of you, flap not your wings}

Before the whole action is completed.

Make haste to distribute the work at once!"

Cooperation combined with brilliant ideas were also the cause of the capture of Khom officers. Nang Chan, mother of P'ra Ruang, led the troops and she uttered,

"Good! Prepare men and weapons with all speed.

Myself will go with you against the foe."

"It is better to run the risk of being considered indecisive, better to be uncertain and not promise, than to promise and not fulfill.",

P'RA RUANG: Are you certain that you will keep your word?

NAK KHUM: I am an officer of the Khom king.

To break my word is quite impossible

P'RA RUANG: Can I be sure of that?

NAK KHUM: You can be sure!

But delay not, act as you have promised

On your part, you also have pledged your word.

Let not your mouth give way to idle boasts.

P'RA RUANG: We Thai never break faith, sir, rest assured.

\section{I shall take counsel with my officers [12]}

This conversation showed how they really value their promises. They basically kept what they promised and marked their words. Their view about promises was far different and the opposite of the saying "Promises are made to be broken".

This was also a manifestation of what is called "palabra de honor" or word of honor. It is like a contract or an agreement between people. All people have to mean what they say and say what they mean. Men should always fulfill what they promised. People should learn how to value their words because that will tell what kind of people they are and thus, it will make or break their reputation to others.

Almost all dramas from Southeast Asia is presented in a physical conflict (Man versus Man) wherein the central character or the protagonist is struggling against the antagonist who opposes to the will of the main character. Dominantly most ASEAN dramas are in social-realism as a genre. Social drama and the social problem play are forms of realism [13].

It is also dominant, in Southeast Asia to have male protagonist in all of its dramas from Malaysia, Philippines, Singapore and Thailand. Majority of antagonist in all Southeast Asian dramas are all male, Father in nature. This clearly shows the patriarchal system dominates the culture of SEA, being authoritarian and the head of the family.

Majority of the SEA dramas are all set or centrally located in a home and happened in the contemporary or present period.

Through the last century, the spirit of modernism and its method of scientific observation has encouraged Southeast Asian artists to grapple with the here and now [14]. This has resulted in plays that now present a gallery of memorable Asian characters all painstakingly delineate peasants, workers, members of the army, social workers, street children, authoritarian parents, king and queen, middle class husbands and wives, impoverished gentry, war heroes and traitors, the urban poor; and a compendium of situations and stories that chronicle the Southeast Asian's various reactions to the institution and changing conditions of Asian society [15]. As a whole, modernism has contributed greatly to the continuing definition of what is proudly SEA and has in this way affected the ASEAN's assessment of what he/she could or should be in the future.

Western realism, which seeks to move an audience through empathy with three-dimensional characters, has been adopted by SEA playwrights, and now follow tendencies: the psychological, which focuses on the problems of individuals; and the social, which situates and roots individual problems within the larger framework of a class society.

Plays of social realism, on the other hand, present contemporary SEA characters and situations. Not all plays, however, could depict urban realities in such a straightforward fashion. Since social conditions in the last eight years inhibited direct expression of protest, playwrights with social messages had to look for subject matter in historical characters and episodes, in order to comment on the present. Probably because of the towering influence of Bertolt Brecht, the expressionistic play of the last decade derived most of its subject matter from folklore.

One of the values present in Inside and Outside the Door is the strong family ties and the love of a parent is unconditional. That whenever one member is in peril Asians as family or relatives wants to protect them from any harm. This identity can overcome barriers between people of Southeast Asia because it is very apparent that values are very similar.

\section{Example Scene:}

Xiao Fang's Father: I'm old and my skin is already thick but my children are different, their skin is relatively thin. They not only have to face the family, they also must face the society. Their ego must be protected. The purpose of that piece of marble is like a protection charm. No! No! It's more than that...

The story After Us serves as an example of having the virtue of oneness of nation. As one of the characters, Sankar, said "We should not be self-centered. We should also care for our nation and other citizens." This proves their willingness to lend a helping hand to others, especially to their neighbouring countries in the South East Asia.

Leela even said that "We should not live for ourselves but for the benefit of others, too." This mindset teaches Southeast Asian people to be more charitable and more united.

It is observed that in some parts of Asia, if one does not 
conform with some of the policies of the government (whatever form of government they have) he can be accused of being a communist or a rebel. This idea is very much seen especially in Luad Suphan. A man can just be considered a leftover soul because once his freedom is taken from him like his detention in jail for an indefinite period of time without any fair trial in court, nothing can be left to hold on, not even a scrap of life to call his own.

The drama Dear Moon in particular can search its identity to overcome barriers between people of the SEA by the implication of the Theme that exists within the play. Most countries in Southeast Asia traditionally engages in arranged marriage, and some regards "love" only as a bridge of their family, to keep the name going, and nothing more or less than that. It teaches Southeast Asians, that there is more to marriage than a cultural aspect and traditional root - it is something divine [16].

It can also represent SEA in the world culturally and socially through its implication of marriage in the line that the aunt presented: "This is Luang Sattanasit, Your wealthy fiancé, pay him your respect" which signifies that we put into thought the ritual of marriage more than anything.

P'ra Ruang shows that a good leader will create good followers. Being on top of his people, they will look up to him. A leader will be their everyone's model. What they see is what they get. What they will do to the other is what they deserved. Good leader should always have solution to the problem but as they say, prevention is better than cure. As a leader, they have to think one step ahead of their constituents.

At the end of the play, the union between Sukhothai Kingdom and City of Lavo happened. The merging between these two will create a powerful kingdom that may somehow threaten the Angkor Thom so they will not put up a fight against them. Unity and peace should always prevail because living in a peaceful place will create good people and good people will create a good nation.

In the Philippines, Gagamutin ang Bayan by Layeta Bucoy, starts off with the boasting of a new dvd player coming from Jess and Boy Pogi. Both of them somewhat take pride in their equipment and its quality, but Jess insists that what Boy Pogi has is only a fake product of sorts- this suggests that the socioeconomic background of the story is low-they also discuss politics in their conversations as they engage in an argument that Boy Pogi should back down in the upcoming election in the city. The state of the community is putrid, both literally and metaphorically, that even the language that exists within that community is slang and colloquial to its roots. Next are the subjects and issue that exists and represents the country's being as a third world country. The idea where there is lack of proper defecting places or comfort rooms in the country, especially at the lower class, is abundant in the story.

There are also hints, rather, direct executions of the implied buying of votes in our country- where it doesnt matter if a candidate running for public office actually competent or not in the terms of running a particular side of society - and the way he just con people into believing him; how a candidate just have to be rich and, for a while, and later screw them up, give them the things that they want and not the things they want equates an automatic role as a politician.
Such can be backed up by Jess's false promises themselves such as how he gave Boy Pogi a new dvd player, fishing net, bait, and all other things along with the promise of money, job-and over-all comfort in life which we can say, has no assurance of sorts coming from him. The political rants continue.

Then comes family ties that exists within the community, which is generally a cultural and traditional background coming from most Southeast Asians [17]. Mang's constant, initial praise towards Jess and his political campaign is proof of that. Jess's persuasion on Boy Pogi-even to the point of buying Boy Pogi's decision, like what politicians usually dobacking out continues as they rant and reminisce things related to their past and what surrounds them right now-society

Today, SEA drama displays a vitality and urgency that surprises theater enthusiasts of whatever persuasion [18]. For one, it is undeniable that this kind of theater has finally come into its own, at least as far as subject matter is concerned.

Asian drama has finally come to fulfill the most basic expectation of a national dramatic theater - the faithful depiction of native reality

As in Europe, many of this contemporary modern plays in the country today are written primarily as vehicles for the individual artist's personal expression of his unique, sometimes, peculiar, view of reality. Using the various techniques of realism and expressionism, most contemporary playwright fall under the banner of art-for-art's sake.

The faithful exposition of SEA society affected by contemporary realistic or expressionistic play goes a long way in creating a scientific view of society that can only redound to the benefit of the general Filipino audience [19]. If such a scientific mentality does spread among the masses, it becomes a potent tool for analysis and weapon for change for uneducated majority.

All told, plays of the contemporary period have already succeeded in faithfully portraying the myriad faces of SEA life today, through the creative use of local and foreign traditions of theatre [20]. When that theater shall also have succeeded. In advancing the interest of Asian economic and political independence, then shall it have grown a little closer to the ideal of a SEA drama.

The potential to represent Southeast Asia of its place in the world can be demonstrated through its dramas by highlighting the identity of Asian drama as a whole. The Asian drama influence can be found in a great variety in Southeast Asian drama forms which somehow molded the Southeast Asian identity. Likewise, the different and varied religious and belief systems found in Asia have also impacted on the identity of the Southeast Asian dramas. These dramas from Southeast Asia has mirrored the dreams and aspirations of its people, not only of the individual countries where the drama originated from, but also Southeast Asia as a whole especially that the move for an ASEAN integration is on its way. The advent of migration also opened a lot of possibilities since there is already the advent of a shared culture between and among citizens, not only of Southeast Asia and Asia, but the rest of the world.

All of these selected dramas reflected the cultural potential of Southeast Asia of its place in the world with emphasis on 
the importance of customs, traditions, folk beliefs, rituals, heritage and identity.

What follows are the individual results for each variable: Thai drama is Historical in nature; All dramas reflected culture specifically unique to their individual countries; Majority of the dramas reflected what is happening in the society most particularly community and family concerns; Educational and Religious Aspect (Hinduism) were both discussed in Singapore

\section{CONCLUSIONS}

With the aforementioned analysis, the following conclusions are given:

1) That the dramas selected expressed the identity of the contemporary Southeast Asia;

2) That there are shared commonalities and differences among the selected dramas of Southeast Asia. Thus, a move for one Southeast Asia can be deemed possible;

3) That the problems, issues, and perspectives presented in the Southeast Asian dramas help overcome barriers between and among its people. Therefore, a niche can be carved for Southeast Asian dramas distinctly its own.

4) That the potential to represent Southeast Asia through its dramas is great as demonstrated by the influence of the Asian drama, religious and culture beliefs as well as other varied influences.

\section{REFERENCES}

[1] A. Bonifacio, Philippine Drama, Quezon City: University of the Philippines Press, 2008, pp. 1-4.

[2] C. Diamonds, Communities of Imagination: Contemporary Southeast Asian Theatres, Honolulu, Hawai'i: University of Hawai'I Press, 2012, pp. 309-313.

[3] J. Brandon, The Cambridge Guide to Asian Theater, USA: Cambridge University Press, 1997

[4] W. Cabasaan, "The cultural traits and values of the selected comics characters from the Philippines, Indonesia, and Malayisa," M.A. thesis, Centro Escolar University, Manila, Philippines, 2010.

[5] M. Novak, "Epigraph," in Carol L. Birch, Unity in Diversity: An Index to the Publications of Conservative and Libertarian Institutions, Metuchen, N.J.: Scarecrow Press: New American Foundation, 1983.

[6] J. Reilly and S. Phillips, Introducing Theater, US: Cengage Learning Inc, Pearson Publishing Company, 2010, pp. 2-7.

[7] P. Nkwi, I. Nyamongo, and G. Ryan, Field Research Into Socio-Cultural Issues: Methodological Guidelines, Yaounde,
Cameroon, Africa: International Center for Applied Social Sciences, Research, and Training/UNFPA, 2001.

[8] L. Dudley, The Humanities, US: McGraw-Hill, Inc., 2009, pp. 64-66.

[9] D. Fernandez, Palabas: Essays on Philippine theatre, Quezon City: Ateneo de Manila University Press, 1996, pp. 8.

[10] A. Juan, The Likhaan Book of Philippine Drama: 1991-1996, Quezon City: University of the Philippines Press, 2000, pp. 1-2.

[11] K. M. Chavalit, Modern ASEAN Plays: Thailand, Office of the National commission for Culture, 1994

[12] R. Daud et al., Modern ASEAN Plays: Singapore, The ASEAN Committee on Culture and Information, 1991.

[13] R. Monsod, "Female empowerment and liberating experience," Bulawan: Journal of Philippine Arts and Culture, vol. 3, pp. 16-19, August 2010.

[14] N. Tiongson, Tuklas Sining: Essays on Philippine arts, Manila: Cultural Center of the Philippines, 1991, pp. 101.

[15] R. Lucero-Derain, "In searching of identities: Analysis of the contemporary poems of selected countries in southeast asia," Ph.D dissertation, Centro Escolar University, Manila, Philippines, 2010.

[16] C. Bico, "Southeast Asian cultural beliefs and values: Reflection from the selected short stories in English," M.A. thesis, Centro Escolar University, Manila, Philippines, 2004.

[17] T. Perez, Tatlong Paglalakbay, Manila: University of Sto. Tomas Publication, 2011, pp. 23.

[18] F. Prudente, The CCP Centennial Honor for the Arts, Pasay City: The Cultural Center of the Philippines, 1998, pp. 16-17.

[19] S. Reyes, From Darna to Zsa Zsa Zaturnnah: Essays on Literature and Popular Culture, Pasig City: Anvil Publication, 2010, pp. 24.

[20] A. Tiatco, "Performing Global at Intelstar: Figuring the Call Center on Manila Stage," Kritika Kultura, Issue 23, pp. 30, 2014.

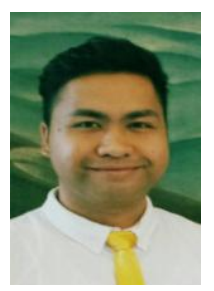

William J. Cabasaan Jr was born in Lipa City, Batangas Philippines. He got a certified academician having an M.A (2010) and $\mathrm{PhD}$ degree (2015) in Southeast Asian Studies from Centro Escolar University, Manila Philippines. He also took up theater arts subject in the University of the Philippines, Diliman, Quezon City. His bachelor's degree is A.B Mass Communication major in Broadcasting also from CEU last 2004

At present he is an assistant professor at the Rizal Technological University in Mandaluyong City teaching literature and humanities. He had done a dozen of productions at Tanghalang Pilipino, the resident theatre company of the Cultural Center of the Philippines, working as an Actor, Stage/ Production Manager since 2004-2010. He also authored books entitled Humanities: Philosophy and History of Art (Malabon City, Philippines: Jimcyville Publication, 2015) and Appreciating Philippine Contemporary Literature (Malabon City, Philippines: Jimcyville Publication, 2014). His research interests include art and cultural studies in the Philippines.

Dr. Cabasaan is the present Auditor of ARTE (Association of Rhetoric and Theatre Educators of the Philippines Inc.) 